\title{
Estigmatización, invisibilización y cosificación de las personas con diversidad funcional. Una aproximación desde la justicia como reconocimiento de Axel Honneth ${ }^{1}$
}

\section{Stigmatization, invisibility and dehumanization of people with functional diversity. An approach from justice in recognition of Axel Honneth}

\begin{abstract}
Resumen
Axel Honneth propone, inspirándose en el joven Hegel, una concepción de la justicia basada en la idea de reconocimiento. Dicha concepción parte del previo acercamiento a una serie de fenómenos negativos, los cuales define como fallas en el reconocimiento. Desde la óptica de Honneth los fenómenos negativos constituyen patologías sociales y formas de injusticia, debido a la falta de calidad moral de las relaciones intersubjetivas. Las consecuencias socio-psicológicas en las personas que los sufren son la construcción de una identidad dañada y dificultades en el logro de la autorrealización. El presente artículo pretende realizar, recogiendo el planteamiento de Honneth, un análisis ético-político de los fenómenos de estigmatización, invisibilización y cosificación sufridos por las personas con diversidad funcional, llegando a la conclusión de que tales fenómenos suponen la negación de la dignidad personal, en la que reside el fundamento de la justicia que nos debemos unos a otros.
\end{abstract}

\section{Palabras clave}

Diversidad funcional, estigmatización, invisibilización, cosificación, reconocimiento, identidad, dignidad, Honneth.

\begin{abstract}
Axel Honneth, inspired by the young Hegel, proposes a conception of justice based on the idea of recognition. This conception results from a prior approach to a series of negative phenomena, which he defines as failure recognition. From Honneth's point of view negative phenomena are social pathologies and forms of injustice, because of the lack of moral quality of intersubjective relationships. The sociopsychological consequences for people who suffer them are the construction of a damaged identity and difficulties in achieving self-realization.

Adopting Honneth's approach this article seeks to make an ethical and political analysis of the phenomena of stigmatization, invisibility and dehumanization suffered by people with functional diversity, concluding that such problems mean the denial of personal dignity, in which the foundation of justice that we owe each other lies.
\end{abstract}

\section{Keywords}

Functional diversity, stigmatization, invisibility, dehumanization, recognition, identity, dignity, Honneth.

\section{Manuel Aparicio Payá \\ <maparici2@yahoo.es>}

Profesor de Filosofía en el IES Aljada, Puente Tocinos (Murcia)
Para citar:

Aparicio, M. (20I6): "Estigmatización, invisibilización y cosificación de las personas con diversidad funcional. Una aproximación desde la justicia como reconocimiento de Axel Honneth", Revista Española de Discapacidad, 4 (I): I77-I9O.

Doi: <http://dx.doi.org/I0.5569/23405IO4.04.OI.IO>

Fecha de recepción: 10-02-2016 Fecha de aceptación: 20-05-2016

I. Este trabajo se inscribe en el marco de la tesis doctoral presentada recientemente por el autor en la Universidad de Murcia, titulada "Trato justo con las personas con diversidad funcional. Reconocimiento e identidad, distribución, inclusión social". 


\section{El modelo social de la discapacidad y la teoría de la justicia como reconocimiento de Honneth}

El modelo social (Barton, I998; Palacios, 2008), formulado en los últimos decenios del siglo $\mathrm{XX}$, viene a superar la concepción naturalista de la dis-capacidad defendida por el paradigma médico y surgido desde el pensamiento científico a partir del siglo XVII. De acuerdo con este nuevo modelo, alumbrado desde la perspectiva del pensamiento emancipador, es necesario distinguir entre discapacidad y diversidad funcional. Por diversidad funcional ${ }^{2}$ se entiende la carencia parcial o total de un miembro, o la posesión de un miembro, órgano o mecanismo del cuerpo que tiene un funcionamiento diferente. Es, pues, un concepto situado en el plano corporal. Por el contrario, el modelo social sitúa la dis-capacidad en un plano diferente. Dicho modelo la concibe como el conjunto de desventajas o limitaciones de la actividad que tienen su origen en el modo de estar organizada la sociedad, cuando se margina o excluye a las personas con diversidad funcional. En suma, lo novedoso del modelo social radica en poner de manifiesto que la dis-capacidad no es un fenómeno patológico meramente natural sino que ha de ser interpretado, más bien, como una patología social, como una forma de opresión (Abberley, 2008) a la que se somete a las personas cuyos cuerpos funcionan de modo diferente al estadísticamente habitual.

\footnotetext{
2. Usamos este término por dos razones: I) De acuerdo con el modelo social, es necesario distinguir entre el funcionamiento corporal diverso de las personas y la discapacidad generada por una sociedad injusta que no lo acoge adecuadamente y 2) Es un término cada vez más empleado en la literatura científica española, introducido desde el modelo de la diversidad funcional (Palacios y Romañach, 2006). Por nuestra parte, entendemos que hay que compatibilizar la diversidad con una concepción universalista que haga descansar la justicia en la dignidad de la persona: un universalismo -como el propugnado por Honneth- que reconozca la diferencia corporal, que valore socialmente a las personas cuyos cuerpos (y mentes) funcionen de modo diferente al estadísticamente habitual. En ese sentido, Honneth apela a la "moral dialéctica de lo universal y lo particular" como base de todas las luchas por el reconocimiento (Fraser y Honneth, 2006: I2I).
}

Desde el modelo social se insiste en que es el conjunto de barreras sociales, económicas, culturales o actitudinales erigidas por acción u omisión, lo que causa la dis-capacidad que afecta a las personas con diversidad funcional. La existencia de tales barreras constituye, por tanto, una forma de injusticia que debe ser rechazada. En último término, lo que aporta el modelo social es una concepción socio-política de la dis-capacidad, así como una nueva imagen social de las personas con diversidad funcional, a las que se empieza a contemplar como sujetos de derechos que, desde un punto de vista éticopolítico, merecen ser tratados con igual justicia.

Por otra parte, en las últimas décadas las distintas concepciones de la justicia se han ocupado de la problemática de las personas con diversidad funcional. Aunque la teoría de la justicia como reconocimiento propuesta por Axel Honneth no aborda específicamente dicha problemática, podemos ver en la misma un enfoque productivo para abordar en qué consiste el trato justo debido a tales personas. En su giro del reconocimiento, que Honneth plantea desde las coordenadas de un pensamiento crítico que sigue la estela de la escuela de Frankfurt, encontramos un acercamiento al tema de la justicia diferente al defendido desde las diversas teorías distributivas de la justicia. En tal sentido, considera (Honneth, 2007: I 46-I47) que las sociedades no solo fracasan normativamente respecto al quebrantamiento de la aplicación de ciertos principios de la justicia de validez general, sino que también pueden hacerlo debido a la existencia de fallas normativas que dañan las relaciones intersubjetivas. Dichas fallas se traducen en un daño moral (Honneth, 20Io: 30) en la dignidad personal, en la medida en que esta no logra ser garantizada a través de relaciones de interacción en las que la persona cuenta con el aprecio de los otros, o en la integridad, en tanto que presenta dificultades para lograr adecuadas autorrelaciones prácticas (autoconfianza, autorrespeto y autoestima) contando con el apoyo social, lo que constituye un peligro para su identidad y para la realización no forzada de aquellos objetivos vitales escogidos por uno mismo (Honneth, I997: 206). En suma, Honneth insiste en la 
importancia que tienen las diferentes formas de ser reconocido por el otro para la configuración no dañada de la propia subjetividad y el logro, en último término, de la autorrealización. Es, pues, una concepción de la justicia que apunta en última instancia a la consecución de una vida buena.

Honneth construye -siguiendo a autores como Adorno o Avishai Margalit- su teoría de la justicia basada en la idea de reconocimiento a partir de un acercamiento a fenómenos negativos, por entender que estos constituyen vías privilegiadas de acceso a los presupuestos normativos correspondientes. Esto supone que el acceso a lo que es la justicia ha de partir metodológicamente de la identificación y comprensión de las distintas formas de injusticia. De ahí que, a lo largo de diferentes trabajos que jalonan su obra, se haya ocupado de describir fenomenológicamente y de justificar teóricamente la existencia de diversas formas prácticas de menosprecio, en las que se produce un fracaso normativo. Honneth interpreta tales experiencias negativas, vividas por el sujeto en sus relaciones intersubjetivas, como patologías sociales (Honneth, 20I I: I I4-I I6), en el sentido de que constituyen alteraciones que deforman las condiciones formales sociales para que los seres humanos puedan lograr su autorrealización. Se trata, por tanto, de formas de vulnerabilidad social que pueden afectar a los seres humanos, dada la existencia de una conexión entre la individualización y los procesos de socialización. La negatividad mostrada en tales fenómenos sociales tiene, a su juicio, un denominador común: la negación o distorsión del reconocimiento. Este concepto de reconocimiento, que Honneth toma del joven Hegel, revisándolo a partir de los estudios empíricos de G.H. Mead es el que, estando ausente o en un segundo plano en tales fenómenos negativos, supone una guía para la reelaboración de una nueva concepción de la justicia centrada en la sensibilidad moral frente a fenómenos de menosprecio. Estas diferentes experiencias sociales, vividas por el sujeto como humillación y falta de respeto, son el resultado de la retirada del reconocimiento social. Es este incumplimiento de las expectativas normativas del reconocimiento lo que constituye, para Honneth, el núcleo central (Fraser y Honneth, 2006: I06-I07) de todas las experiencias de injusticia. Establece así una equivalencia entre el concepto teórico de injusticia y el incumplimiento de las expectativas normativas de los sujetos respecto al reconocimiento de su integridad personal, en el marco social de un orden de reconocimiento (Honneth se refiere aquí, en concreto, al orden de reconocimiento propio de la sociedad capitalista occidental actual).

En este artículo nos centramos en una serie concreta de fenómenos negativos: el análisis efectuado por Honneth de la estigmatización, la invisibilización y la cosificación, aplicándolo por nuestra parte al ámbito de la diversidad funcional. Aunque tales fenómenos sociales no afectan exclusivamente a las personas con diversidad funcional, sí cobran especial relevancia en sus vidas: constituyen -vistos desde la óptica del modelo social- barreras actitudinales que, conectadas a factores culturales, económicos o sociales pueden erosionar las relaciones intersubjetivas en las que dichas personas toman parte, con las consecuencias antes señaladas.

2. El fenómeno de la estigmatización de las personas con diversidad funcional

Una de las formas de humillación moral (Honneth, I997: I48-I 59) es la que tiene que ver con la desvalorización social del modo de vida del individuo o del grupo. Se trata de una injusticia de carácter cultural-valorativo en la que se degrada el valor social de ciertas formas de autorrealización, producida en el horizonte de la tradición cultural. El daño que se produce al individuo (o al grupo) proviene de que sus capacidades y su modo de vida dejan de poseer importancia para la comunidad concreta en la que se integra. La consecuencia de este tipo de menosprecio radica en que, bajo el influjo de la cultura dominante, el individuo (o el grupo) 
no puede atribuir un significado positivo a su modo de vida en el seno de una comunidad concreta. Lo que ahora está en juego a través del conflicto cultural (Honneth, I997: I64) es la pérdida de la aceptación social de una forma de autorrealización que la persona singular tiene que encontrar con la ayuda de la solidaridad comunitaria. De ahí que la persona, en la medida en que no se vea estimada en sus cualidades específicas, deja de identificarse con ellas y sufre una pérdida en su autoestima, con el consiguiente daño a su identidad y al logro de la autorrealización. Es lo que ocurre con la estigmatización. En tanto que esta sirve de base a unas relaciones intersubjetivas que suponen la desvalorización social de las personas estigmatizadas, impide o dificulta el surgimiento de relaciones solidarias activas, lo cual repercute en que las personas afectadas puedan desarrollar adecuadamente su autoestima. Esta forma fallida de reconocimiento social, como ya señalara Goffman (2006) desde el interaccionismo simbólico, está ampliamente extendida, afecta de un modo u otro a la mayoría de la población e implica roles -el estigmatizado y el normal- que son reversibles en el mismo individuo. La comprensión de las bases psicológicas de este fenómeno social es relevante, en la medida en que impone a la víctima un obstáculo o limitación al logro de su autoestima. Para Honneth, la estigmatización constituye un freno a la libertad (Honneth, 20IO: 3I) o espontaneidad que requiere la autorrealización, no solo porque existe una presión externa sobre el estigmatizado, sino también porque en él se produce un bloqueo interno. A su vez, también existe un bloqueo psicológico en el estigmatizador, que daría origen a la conducta humillante que daña a la persona estigmatizada.

Iris Young y Martha Nussbaum también han tratado de explicar el origen psicológico de la conducta de estigmatización hacia las personas con diversidad funcional, recurriendo para ello -aunque con diferencias- a la teoría psicoanalítica. Ambas autoras sitúan la raíz psíquica de este fenómeno social de humillación en la etapa infantil, en relación a la experiencia de dependencia originaria y al posterior proceso de separación del infante, vivido por él de forma dolorosa respecto a la madre o persona principal de referencia que le proporciona el cuidado amoroso.

Young (2000) considera que el imperialismo cultural es una forma de opresión proyectada por los grupos dominantes sobre aquellos grupos cuyos cuerpos son construidos con desprecio. Dicha proyección cultural es la responsable de convertirlos en cuerpos marcados, ante cuya presencia los otros sienten, de forma inconsciente, nerviosismo o aversión. Para explicar el mecanismo psíquico que está en la base de la proyección cultural de esta marca o estigma, Young retoma el concepto de lo abyecto (Young, 2000), formulado desde el psicoanálisis por Julia Kristeva. Este concepto hace referencia a un sentimiento de aversión y repugnancia que tiene el sujeto cuando se enfrenta a ciertas imágenes y fantasías, ante las que se responde con rechazo. Lo abyecto surge en edades tempranas del niño, en el momento de separación o ruptura de la simbiosis con la madre (o persona que principalmente lo cuida). Tal separación, vivida por el infante como una pérdida, supone la formación de una frontera entre un yo todavía no formado y la persona de referencia, lo cual da lugar a un sentimiento irracional de aversión y repugnancia hacia el cuerpo de la misma. Esta reacción inconsciente e irracional aparecerá en otros momentos de su vida para afianzar la frontera que delimita al yo respecto al otro estigmatizado. Así pues, Young remite el significado de la estigmatización al rechazo del otro, en el sentido de mantenimiento de la frontera de separación con él, salvaguardando de ese modo la propia identidad. Lo abyecto se rechaza porque supone una amenaza, surgida con la presencia de la persona estigmatizada, a la propia identidad.

Young sugiere que el concepto de lo abyecto permite explicar, al menos en parte, la discriminación de las personas con diversidad funcional, consideradas por la cultura dominante, desde un prisma estético, como cuerpos feos y temibles que producen reacciones de aversión. Tal consideración responde, a su juicio, a una construcción simbólica: en un 
contexto cultural e histórico determinado se produce una asociación cultural que vincula a dichas personas con la idea de degeneración corporal o de muerte.

Una consecuencia derivada de esta proyección cultural sería la consideración de las personas con diversidad funcional como alteridades abyectas, a las cuales se trata de mantener al otro lado de la frontera mediante reacciones inconscientes de aversión. Otra consecuencia señalada por Young es la que afecta internamente al sujeto estigmatizador, por cuanto en este se produciría la represión de la heterogeneidad en el sentido de su yo: la cercanía de la persona con diversidad funcional enfrenta al normal a su propia -real y posible- diversidad funcional. Mediante la estigmatización, el sujeto estigmatizador no solo construye una frontera que le separa del otro, también erige una frontera que le aísla de aquellos aspectos de sí mismo que no es capaz de afrontar.

Para Young es necesario que cada uno se responsabilice de las manifestaciones de su comportamiento estigmatizador, no tanto para la preservación de la propia salud psíquica sino, fundamentalmente, por el daño provocado a las personas estigmatizadas y la contribución al mantenimiento de la opresión. Tal responsabilidad exige que el individuo se comprometa con la justicia social y haga frente a la estigmatización: solo cuando los individuos efectúen una reflexión tendente a modificar sus hábitos y actitudes podrán cambiarse las condiciones socio-culturales de la opresión. Su propuesta para amortiguar la estigmatización, más allá de la aplicación de los métodos psicoanalíticos, estriba en una doble medida: I) incidir en la desconexión cultural entre los grupos despreciados y la abyección, mediante la creación de condiciones sociales igualitarias para que tales grupos se redefinan culturalmente a sí mismos de forma positiva y 2) tomar conciencia, a través de procesos educativos, de la repercusión en el otro de las reacciones de aversión que una persona puede tener. Este segundo aspecto contribuye también a que dicha persona pueda construir una identidad heterogénea, enfrentando así su propia -al menos potencial- diversidad funcional y la aceptación de su mortalidad.

También Nussbaum se ha ocupado de elaborar una teoría acerca del origen y significado de la conducta estigmatizadora, apoyándose en este caso en la teoría psicoanalítica de la relación de objeto de Donald Winnicott, Melanie Klein y otros autores. Nussbaum analiza esta forma de humillación social recurriendo a una explicación de la vergüenza, a la que concibe como una emoción universal surgida en la infancia. Establece una estrecha relación entre ambas, en la medida en que la estigmatización tiene la intención de provocar vergüenza en la persona estigmatizada (Nussbaum, 2006: 209-210).

Nussbaum sitúa el origen de la emoción de la vergüenza en el fenómeno antropológico de indefensión, propio de la llegada al mundo de los miembros de la especie humana, y en la correlativa dependencia respecto a la persona de referencia (madre, padre, etc.), la cual le proporciona cuidado y permite la satisfacción de sus necesidades.

La explicación psicoanalítica de la vida del niño recogida por Nussbaum muestra que este va pasando de una etapa caracterizada por una relación simbiótica con la persona que le ama y cuida, en la que también proyecta su ira cuando no ve atendidas sus necesidades, a una etapa de progresiva separación e independencia, en la cual espera ser valioso y perfecto. Cuando sea más consciente de no poder alcanzar la perfección que considera que debería tener, surgirá en él la emoción de la vergüenza, como intento de ocultamiento de dicha imperfección. Con el tiempo, el individuo va venciendo su narcisismo y aprende a no tener vergüenza por la dependencia que tiene para la satisfacción de sus necesidades. Empieza a percibirse como un ser incompleto y aprende a desarrollar relaciones de reciprocidad e intercambio con los demás, a los que también percibe como incompletos e imperfectos. Sin embargo, en este proceso psíquico tiene una enorme influencia la socialización que se da tanto en la familia como por la cultura en su conjunto. Tal influencia provoca que el resultado de dicho 
proceso sea variable y, como consecuencia del mismo, puedan surgir patologías. La vergüenza primitiva puede ser modelada por las instancias socializadoras en una doble dirección: puede educarse en la asunción de la vulnerabilidad y la dependencia propias, favoreciendo así una vergüenza constructiva, o bien puede hacerse de forma que las mismas se perciban como algo de lo que uno mismo tendría que avergonzarse, lo que le llevaría al ocultamiento de sus debilidades.

Para explicar la estigmatización, Nussbaum lanza una conjetura: pone en relación la explicación sociológica de Goffman con el proceso psicológico descrito por la teoría psicoanalítica. Contempla este fenómeno desde la perspectiva del individuo estigmatizador, considerando que la construcción de la categoría ficticia de normalidad tiene como finalidad la estigmatización de los individuos diferentes y responde al desarrollo de la vergüenza primitiva (Nussbaum, 2006: 254-259), que es experimentada universalmente. Al definirse como normal, el individuo busca ocultar sus propias debilidades, ya que estas le causan vergüenza. Con ello, busca conseguir una seguridad sustitutiva de aquella otra seguridad que el infante encontraba en su etapa de simbiosis con la madre o persona de referencia. Tal seguridad ilusoria la encuentra mediante el rechazo de aquellos que son diferentes. En ese sentido, Nussbaum concibe la estigmatización como una reacción de agresividad que consistiría en lanzar la vergüenza propia hacia fuera, hacia los diferentes: "la vergüenza en el ser a menudo lleva al deseo de que otros sientan vergüenza y a practicar la humillación y el avergonzar activo que infligen un estigma a personas y grupos vulnerables” (Nussbaum, 2006: 257).

Una sociedad decente, a juicio de Nussbaum, sería aquella capaz de crear un ambiente facilitador (Nussbaum, 2006: 324) para que los ciudadanos pudiesen desarrollar una vida libre de estigma. Es por eso que considera necesario construir una sociedad que facilite relaciones intersubjetivas sin humillación, basadas en el respeto mutuo entre los ciudadanos. En el caso de las personas con diversidad funcional, tal protección vendrá dada, según Nussbaum, por: a) la existencia de leyes que combatan la humillación pública y la discriminación, b) el rediseño de los espacios públicos y los ordenamientos sociales para facilitar su presencia pública (en el mundo del trabajo, de la educación, de la actividad pública, etc.) y c) por la implementación (Nussbaum, 2006: $355)$ de prácticas informales de educación moral y de debate social que cuestionen el mito de la perfección que subyace a la concepción del ciudadano presente en el pensamiento político occidental.

Desde el punto de vista teórico, propone (Nussbaum, 2007) una revisión de la teorías de la justicia basadas -desde Hobbes hasta la versión kantiana de Rawls- en el contrato social, sustituyéndolas por el enfoque de las capacidades iniciado por el economista Amartya Sen. Nussbaum concibe las capacidades como "formas de hacer efectiva una vida con dignidad humana en las diferentes áreas de actividad de una vida humana típica" (Nussbaum, 2007: I69). Entre el conjunto de capacidades básicas que definen la justicia social incluye la afiliación o capacidad de poder vivir con otros y ser tratado como un ser dotado con dignidad e igual valor (Nussbaum, 2007: 89). La introducción de esta capacidad, en la que se nota la influencia de la concepción de la justicia de Rawls (I979: 208), supone un acercamiento, desde una teoría distributiva de la justicia, a la noción de reconocimiento. En la medida en que el respeto propio depende del respeto otorgado por los demás, deben darse las bases sociales para que los individuos no sean humillados y puedan desarrollar el autorrespeto. Cuando alguna persona (o grupo de personas) no alcance el mínimo en la capacidad de afiliación, es decir, cuando no sea respetada, entonces hay, a juicio de Nussbaum, razones imperiosas de justicia para que la sociedad -al menos hasta un umbral mínimo- implemente un abanico amplio de medidas para que pueda tener el reconocimiento de los demás y logre el autorrespeto.

No obstante, Nussbaum no explica cómo la sociedad avanza hacia la justicia. Es Honneth el que conecta los sentimientos negativos de 
humillación sufridos por las personas (o grupos de personas) con la lucha por el reconocimiento, mostrando así el mecanismo explicativo que impele a la sociedad hacia la justicia.

Desde el planteamiento de Honneth cabría considerar que la estigmatización deja fuera del nosotros comunitario no solo a aquellos otros a quienes se les considera anormales; al producirse un rechazo de la diferencia, también dejaría de incluir la propia vulnerabilidad corporal y dependencia de los normales. Esta termina así expulsada de la configuración de la identidad. Por ello, la falla en el reconocimiento social que supone la estigmatización no solo afecta a la autoestima de quien ve negado dicho reconocimiento sino que, de modo reflexivo, socava también, en un plano inconsciente, la propia autoestima del sujeto en quien aparece este tipo de discriminación. En cierto modo, puede decirse que el individuo que estigmatiza también proyecta sobre sí su propio rechazo y desvalorización, en la medida en que se ve incapaz de soportar su propia vulnerabilidad corporal y su propia dependencia.

En el planteamiento de Honneth, que también recoge el paradigma psicoanalítico, encontramos cierta coincidencia con el tratamiento efectuado por Nussbaum. Honneth revisa el legado aportado por Freud y defiende la tesis de que la principal aportación de la teoría freudiana, que considera todavía vigente, es "haber comprendido que el ser humano en principio siempre es un ser escindido, desgarrado, pero que gracias a su interés intrínseco por ampliar su libertad 'interior' posee la capacidad de reducir o incluso de superar ese desgarramiento mediante la actividad propia, reflexiva" (Honneth, 2009: I40).

Aunque Honneth no se ocupa específicamente de la estigmatización de las personas con diversidad funcional, se podría interpretar -en relación a la cuestión de soportar la vulnerabilidad física y la dependencia propias, como posibilidades siempre abiertas- que en el sujeto estigmatizador se da una escisión, en el sentido de rechazo de la propia vulnerabilidad. Dicho rechazo repercute, de acuerdo con el planteamiento freudiano, en la limitación de la dimensión interior de su libertad individual. En tal sentido, Honneth alude al proceso reflexivo apuntado por Freud, también en individuos psíquicamente sanos, con el que se intenta la superación de dicho desgarramiento interior. Podríamos decir, a partir del pensamiento de Honneth, que esta reestructuración de la relación consigo mismo, mediante la cual el sujeto se apropia afectivamente del temor que genera la propia vulnerabilidad y dependencia, es lo que permite reconducir dicha escisión antropológica hacia un desarrollo adecuado de la autonomía individual y un reconocimiento positivo de los "otros como yo" vulnerables y dependientes.

No obstante, Honneth se acerca, como Nussbaum, a una versión del psicoanálisis -la teoría de la relación de objetos- distinta a la freudiana, esbozando una concepción del mismo acorde con su teoría del reconocimiento. De acuerdo con esta idea, Honneth hace depender la transformación de la relación consigo mismo de la mediación intersubjetiva. En ese sentido, considera que la génesis del psiquismo interior depende de la interiorización de las relaciones de interacción con la madre o las personas de referencia, es decir, de la relación intersubjetiva de cuidado, en la que se da el reconocimiento afectivo del otro concreto. En ese primer modelo, la clave será lograr un equilibrio entre la relación simbiótica y la independencia del yo, a través de los objetos de transición. Este es el mismo equilibrio que el adulto tendrá que intentar mantener a lo largo de su vida para ganar la libertad interior, mediante un diálogo fluido entre las instancias psíquicas (yo, superyó y ello). Dicho diálogo no es sino la interiorización del equilibro en las relaciones intersubjetivas externas (siguiendo el modelo del cuidado infantil) (Honneth, 20I I: I83-204).

Por otra parte, la estigmatización no constituye para Honneth solo una forma cultural ${ }^{3} \mathrm{de}$

3. No podemos entrar en este artículo en el desarrollo de la polémica entre N. Fraser y A. Honneth (Fraser y Honneth, 2006), aunque cabe señalar aquí la diferencia entre ambos autores respecto a esta cuestión. La teoría bidimensional de la justicia de Fraser enmarca la estigmatización en el ámbito del reconocimiento erróneo cultural, aunque pueda tener 
injusticia, sino que también tiene para él una raíz económica ya que, en su opinión, guarda relación con el mundo del trabajo. Honneth recurre aquí al modelo de la división cooperativa del trabajo introducido por Mead (Honneth, I997: I48). A su juicio, la transición histórica que supuso la modernidad conllevó la escisión del concepto pre-moderno de honor en dos ideas opuestas: "una parte del honor garantizado por la jerarquía se democratizaba, en cierto sentido, al otorgarse a todos los miembros de la sociedad un respeto igual por su dignidad y autonomía como personas jurídicas, mientras que la otra parte quedaba "meritocratizada», en cierto sentido: cada uno disfrutaría de la estima social según su éxito como "ciudadano productivo" " (Fraser y Honneth, 2006: I I 2). De acuerdo con esto, esta forma de menosprecio tiene que ser concebida como una pérdida de estima social derivada de la falta de éxito en el ámbito económico de la producción, con consecuencias perjudiciales en la distribución y en el consumo de bienes. Lo que queda cuestionado en esta forma de humillación son las habilidades y talentos valiosos que pueden ser aportados por parte de los individuos humillados al mundo del trabajo. Lo que está presente en esta forma económica de menosprecio social son los valores culturales. Honneth es consciente de las distorsiones valorativas que subyacen en la interpretación cultural de lo que se considera éxito o trabajo, algunas de las cuales están relacionadas con el pensamiento naturalista (Fraser y Honneth, 2006: I I 7). Puede decirse, recogiendo lo afirmado por Honneth, que el naturalismo se ha utilizado, en muchos casos, para restar valor al esfuerzo productivo realizado por las personas con diversidad funcional, menoscabando así sus posibilidades de inclusión laboral; también para no estimar

consecuencias en la distribución económica. Sin embargo, Honneth rechaza que la estigmatización quede limitada al ámbito cultural, ya que afecta también a la dimensión económica. Otra diferencia tiene que ver con las consecuencias de la estigmatización: para Fraser, constituye una limitación a la participación no coercitiva en la vida pública; para Honneth lo relevante, en último término, es que afecte a la autorrealización. No obstante, Honneth señala que ambos coinciden en que la estigmatización impide "mantener y practicar públicamente sus estilos de vida sin vergüenza ni humillación” (Fraser y Honneth, 2006: I92). socialmente o restar valor a las actividades del cuidado de personas dependientes. Podemos decir entonces que las dis-capacidades en el ámbito del trabajo no responden a factores naturales, sino a la falta de acomodación social de las personas con diversidad funcional en dicho mundo del trabajo (potenciación de capacidades existentes, accesibilidad universal, medidas de incentivación para la inclusión laboral, etc.), lo cual repercute en el ejercicio de la ciudadanía económica.

Por eso mismo, el cambio social en este terreno exige una lucha por la transformación del horizonte valorativo compartido socialmente. En ese sentido, Honneth indica que la lucha por superar esta forma de menosprecio se convierte en una lucha simbólica de los diferentes grupos -en este caso, la lucha por el reconocimiento promovida por las personas con diversidad funcional y quienes les dan su apoyo- por aumentar el valor social de sus miembros en el seno de la comunidad, dada la repercusión económica que tiene dicha estima social en el nivel de rentas de los miembros del grupo (Honneth, I997: I 56).

También Young concibe el prestigio como una construcción cultural y simbólica (Young, 2000: 373), de la que se hace depender la recompensa material diferencial. Young cuestiona la idea de la existencia de un criterio objetivo del mérito (Young, 2000: 336-353), no sesgado normativa y culturalmente, para la valoración del desempeño individual en el trabajo. En la medida en que los criterios de evaluación del mérito responden a los valores culturales de los grupos dominantes, no tienden tanto a llevar a cabo una evaluación neutral del mérito en el desempeño del trabajo, sino que contribuirían, más bien, a mantener y reproducir las ventajas de tales grupos, en detrimento de las personas pertenecientes a los grupos culturalmente subordinados. Desde su punto de vista no sería posible, pues, una evaluación neutral de la competencia técnica, ajena a todo tipo de valoración. De este modo, las personas con diversidad funcional pueden verse afectadas en dicha valoración, en tanto que los criterios utilizados no recogieran la diferencia 
corporal existente sino que se ajustasen a las capacidades y cualidades de los grupos de personas normales. Young también señala que en dicha evaluación podrían incluirse los prejuicios inconscientes hacia las personas con diversidad funcional, lo que podría traer como consecuencia su discriminación laboral: ante un currículum similar, podría deslizarse una valoración negativa de la persona con algún tipo de impedimento, frente a una valoración más positiva de un candidato encuadrado en la escala cultural de normalidad. Por ello, defiende que la evaluación del mérito sea política (Young, 2000: 354-359) y que debe establecerse democráticamente, incluyendo a personas de los grupos desventajados. De esta forma se asegura que la experiencia, los valores y cultura particulares de todos los grupos sean recogidos en la deliberación y argumentación que sirva de base para el establecimiento de tales criterios.

\section{Invisibilidad y cosificación de las personas con diversidad funcional}

Axel Honneth también se ha ocupado de la cuestión de la invisibilización como una forma de humillación social. En el artículo "Invisibilidad. Sobre la epistemología moral del 'reconocimiento"” (Honneth, 20I I: I65I8I) aborda este fenómeno remitiéndolo, desde una fenomenología negativa, a la falta de un adecuado reconocimiento. Dicha invisibilidad respondería a una disposición interior de aquellos que "miran a través" del otro, demostrándole así un desprecio que anularía su presencia física en el espacio en que tiene lugar la interacción. Podemos señalar que este fenómeno se da también, con bastante frecuencia, en la interacción cotidiana que tienen las personas con diversidad funcional. Sometidas como están a continuas observaciones, terminan convirtiéndose, en numerosas ocasiones, en personas ignoradas, debido a su invisibilización. Así, por ejemplo, puede darse la circunstancia de que una persona con diversidad funcional física o sensorial que vaya acompañada se encuentre con alguien que pretende preguntarle algo. Tal persona puede resultar finalmente ignorada si la pregunta no fuese dirigida a ella directamente, sino que se la formulasen a su acompañante.

En ese sentido, las personas con diversidad funcional que no tienen dificultades de aprendizaje son percibidas como 'eternos niños', incluso en el trato con profesionales. Así, por ejemplo, en un estudio sobre la experiencia de mujeres con diversidad funcional, Nasa Begum cuenta la experiencia con el médico de atención primaria de una de ellas: "Aunque él sabía que iba a la universidad, seguía tratándome como a una niña. En una ocasión, cuando me estaba desnudando antes de una exploración, respondí a través del biombo y en voz muy alta a preguntas dirigidas a mi madre que debería haberme hecho a mí” (Begum, I997: 203). Para Honneth, lo que fallaría en esta forma de mirar al otro no es tanto el conocimiento de dicha persona cuanto su reconocimiento. $\mathrm{La}$ invisibilidad no sería un hecho cognitivo, de modo que la persona perceptora no captara las características que identifican claramente a la persona observada. Estaríamos, más bien, ante un estado de cosas social, (Honneth, 20I I: I67) según el cual la persona observada no se siente percibida, lo cual entiende como un signo, más o menos sutil, de humillación.

Honneth considera que en el fenómeno de la invisibilidad se mostraría la existencia de la primacía genética (Honneth, 20I I: I79-I80) del reconocimiento sobre el conocimiento. En el caso de las personas con diversidad funcional, estos rasgos identificativos son claramente percibidos en la medida en que constituyen rasgos diferenciadores: por ejemplo, "aquella persona que camina con su bastón”, "aquel otro que se desplaza en silla de ruedas", "el chico que se comunica mediante lenguaje de signos", etc. A pesar de la facilidad con la que se produce dicha identificación cognitiva, la persona observada, en muchas ocasiones, no se siente reconocida cuando se produce el encuentro intercorporal e intersubjetivo. Lo que faltaría en tales casos, a tenor de lo que piensa Honneth, sería la obtención de reconocimiento. En el contexto 
del citado artículo entiende por reconocimiento como un "acto expresivo mediante el cual es conferido a aquel conocimiento el significado de una apreciación" (Honneth, 20I I: I70). Esta forma elemental de reconocimiento tiene lugar, para Honneth, en el plano de las expresiones corporales, cuando se produce el encuentro interactivo entre personas de "carne y hueso", en la presencia mutua de cuerpos personales, de sujetos encarnados.

Lo que falla en la invisibilidad, por tanto, son las acciones, los gestos o las palabras (una sonrisa o un gesto de bienvenida, un acto de saludo, gestos de agradecimiento, etc.) que, como comportamiento expresivo positivo, esperamos unos de otros y que confirman nuestra existencia social. Cuando faltan tales expresiones corporales lo que se experimenta, por el contrario, es el desprecio social. Cabría añadir que, con tal supresión expresiva, lo que se estaría produciendo sería la negación de la presencia ética que supone la corporalidad del otro. En otras palabras, si somos vistos en el mundo social a través de nuestro cuerpo, la invisibilización de las personas con diversidad funcional vendría a significar el rechazo a su corporalidad en cuanto a su funcionamiento diferente. Para Honneth, esta forma variable de humillación no solo sería captada por la persona afectada sino que, dado su carácter público, otras personas también podrían darse cuenta de lo que está ocurriendo. En virtud de la existencia de una gramática de la comunicación gestual (Honneth, 20I I: I77-I78) culturalmente construida, pueden surgir en otras personas reacciones de rechazo o de indignación cuando capten que a aquellas personas con diversidad funcional que no puedan llegar a ser conscientes de esa humillación, se les niegan tales gestos expresivos o, sin negárselos, se hace una utilización instrumental de los mismos.

Honneth se remite, en apoyo de su fenomenología de la invisibilidad, a la comunicación gestual que tiene lugar en la interacción entre el niño y la persona de referencia (padre/madre). La sonrisa o los gestos de la persona de referencia hacia el niño serían expresiones de aprobación. Más que de un conocimiento de que se está en presencia de un niño pequeño necesitado de ayuda, se trataría de la emisión de señales aprobatorias que simbolizarían, de forma abreviada, la totalidad de las acciones encaminadas a la realización práctica de los cuidados que el niño pequeño necesita. Más que un acto cognitivo, se trataría de un acto moral llevado a cabo por la persona de referencia en el que, de forma abreviada, se da a conocer al niño que goza de su amor y que está dispuesta para la realización de las tareas que su cuidado requiere: "el reconocimiento posee un carácter performativo, porque las expresiones que le acompañan simbolizan aquellas formas de reacción que serían necesarias para "hacer justicia» a la persona reconocida. Con una bella formulación de Helmuth Plessner, se podría decir también que la expresión del reconocimiento representa aquí la "parábola» de una acción moral" (Honneth, 2OII: I72).

La comunicación gestual juega también, a juicio de Honneth, un importante papel en la interacción social entre adultos. En los rituales de saludo de las personas adultas también se da el mismo tipo del señales aprobatorias, las cuales vendrían a mostrar abiertamente a la persona a la que van dirigidas que, con dicha forma de comunicación, se le está dando visibilidad o aprobación social, o se valora el rol desempeñado por ella. La supresión de estas formas de expresión constituye un indicador de la existencia de una patología social, potencial generadora de un estado de invisibilidad en la persona afectada. A su vez, Honneth remite toda otra forma de reconocimiento social (Honneth, 20I I: I74) a las conductas expresivas de las personas que están enfrente, en la medida en que, de ese modo, la persona se sabe reconocida socialmente de una forma elemental, garantizando con ello su visibilidad social. Para Honneth, pues, el reconocimiento social tiene en la base, como mecanismo fundamental y como forma elemental, el comportamiento expresivo dado en la interrelación corporal e intersubjetiva. La invisibilidad, como fallo en este modo elemental de reconocimiento, afecta a las formas posteriores de reconocimiento social (amor, respeto, solidaridad) y supone 
un menosprecio de índole moral, por cuanto la ausencia de un comportamiento expresivo hacia el otro denota aquí la negación de su valor como persona, en el sentido kantiano. Honneth establece, pues, una conexión entre esta concepción del reconocimiento y la concepción kantiana de dignidad: este valor incondicionado que se concede al otro puede hacer que se le considere, de acuerdo con las diferentes esferas de reconocimiento, como digno de amor, digno de respeto o digno de solidaridad.

En consecuencia, la invisibilización de las personas con diversidad funcional es la forma elemental del menosprecio social y tiene un carácter inmoral: convertirlas en seres humanos y ciudadanos invisibles es negar su dignidad de personas (que no deben ser instrumentalizadas y que deben ser empoderadas), es ignorar o rechazar su estatus de poseedores de iguales derechos. En definitiva, la invisibilización, como denegación del reconocimiento, supone dejar de considerar al otro como persona, como un ser moralmente valioso.

Otra de las patologías sociales relacionados con la ausencia de reconocimiento abordadas por Honneth es la cosificación (Honneth, 2007). Dicha patología social consiste en que, en la interacción social, se deja de ver a otros seres humanos como personas y pasan a ser considerados como cosas. Este fenómeno vendría producido, según Honneth, por un "olvido del reconocimiento" (Honneth, 2007: 9I-96). La amnesia constituye para Honneth el núcleo de todo proceso de cosificación. Consiste en la pérdida de la capacidad de sentir que el conocimiento de una persona depende de un previo reconocimiento. La consecuencia de este olvido será la consideración del otro como un objeto insensible y no como persona. La cosificación supone la ruptura del sentimiento de unión con el otro, supone tratar al otro como un objeto puramente observable, carente de toda emoción o sensación. Honneth señala dos casos ejemplares de cosificación (Honneth, 2007: 9697 y I37-ss.):

a. Cuando, en la praxis social, la observación cognitiva del otro cobra tal intensidad que constituye un fin en sí mismo. Se pierde la atención sobre el reconocimiento previo que se le tenía, extinguiéndose así la conciencia de la relación social. Honneth pone el ejemplo trivial del jugador de tenis que juega con un amigo y, al concentrarse tanto en el juego, olvida la relación de amistad que es la que le condujo al partido que está jugando. Dentro de este caso paradigmático podría incluirse un ejemplo menos trivial: la situación de aquellas personas que, por alguna circunstancia, adquieren una diversidad funcional cuando son adultos. En tal caso, algunas personas de su entorno laboral o de sus círculos de amistad pueden comenzar a tratarlos de modo diferente, debido a que focalizan fuertemente su atención en el impedimento adquirido. Aunque tal persona no haya perdido otras competencias y mantenga plenamente la capacidad de mantener relaciones sociales, puede que la intensidad de tal observación haga que algunas personas que interactúen con él, bien en el terreno profesional o bien en el ámbito de las relaciones personales, termine por perder la capacidad de sentir dicha relación social. Otro ejemplo no trivial que también podría incluirse aquí sería el referido a la relación profesional de atención y cuidado a personas dependientes. Las personas que se dedican a tales tareas profesionales requieren (Etxeberría, 2005: I06), a pesar de su carácter contractual, cierta dosis de empatía. Al igual que ocurre con otras personas en diferentes profesiones de asistencia, el trabajo especializado de asistencia a personas dependientes, sobre todo cuando se desarrolla con una elevada intensidad, puede terminar por convertirse en una relación en donde surja la cosificación, en la medida en que se olvide el reconocimiento empático de la persona asistida.

b. El segundo caso paradigmático expuesto por Honneth, ejemplificado por él en el racismo, sería la existencia de un sistema de convicciones y prejuicios, en cuyo caso, más que tratarse de un 'olvido', se trataría de una 'negación' o 'resistencia', en la 
cual no solo interviene una perspectiva del mundo enraizada culturalmente. También la praxis social estaría interactuando con dicha concepción cultural, de forma que sería la conjunción de ambos factores lo que causaría la cosificación o pérdida de la humanidad de las personas. Aquí nos podemos referir, obviamente, a los esquemas de pensamiento y a las bases culturales sustentadoras de los procesos de estigmatización de las personas con diversidad funcional.

En el contexto de su obra 'Reificación' (Honneth, 2007), este autor se remite a una nueva manera de entender el reconocimiento. Aquí se refiere a un modo 'existencial' del mismo, que origina todas las demás formas del reconocimiento. Honneth la describe como una 'implicación afectiva' (Honneth, 2007: 80-8I) con la persona de la que obtenemos un posterior conocimiento. Apoyándose en la psicología evolucionista, muestra Honneth la preeminencia del reconocimiento, como identificación emocional con el otro, sobre el conocimiento. También muestra, recurriendo a Lukács, Heidegger, Dewey y al planteamiento analítico de Stanley Cavell, la preeminencia categorial del reconocimiento.

En consecuencia, en las diferentes formas de cosificación encontramos la pérdida de la conexión afectiva con el otro, quedando reducida ahora la praxis social a una mera conexión cognitiva, en la cual el otro resulta meramente observado. En el fenómeno de la cosificación o deshumanización dejamos de ver a otros seres humanos como personas y pasamos a contemplarlos como objetos meramente observables. Aunque Honneth no hace aquí referencia expresa a Kant, de nuevo podemos ver en esta patología social la distinción kantiana entre cosa y persona (Kant, I980). La cosificación de los seres humanos, también en el caso específico de los seres humanos con diversidad funcional, supone su deshumanización, el olvido de que estamos ante personas que tienen dignidad y no precio, ante seres que no deben ser instrumentalizados y que deben ser empoderados en sus cualidades personales (Cortina, 2007), ante miembros de la comunidad social y política que no deben ser meramente observados, sino de la que deben ser considerados participantes en la praxis social y política con iguales derechos y con iguales condiciones de acceso a los mismos, tanto para el ejercicio de su autonomía privada como para el ejercicio de su autonomía pública (Honneth, 20I4).

\section{Reconocimiento de las personas con diversidad funcional}

Honneth subraya la importancia de ser tratados justamente, en el sentido concreto de ser reconocidos por los otros en distintas formas de relación intersubjetiva, de las que depende el surgimiento de una subjetividad no dañada. Hemos ido viendo cómo la estigmatización, la invisibilización o la cosificación constituyen, para Honneth, patologías sociales que suponen un daño moral de tales relaciones intersubjetivas, lo que conlleva daños en la identidad y en el ejercicio de la autonomía individual. Tales fenómenos se muestran como negaciones de la dignidad que -en concreto- las personas con diversidad funcional comparten con las demás personas. Por contra, la otra cara de la moneda la representa el reconocimiento, en las distintas esferas (afectivo, jurídico-moral y solidario) a las que alude este autor (Honneth, I997). La inclusión de las personas con diversidad funcional en las distintas redes sociales de reconocimiento supone la reafirmación de la dignidad que tienen como personas, como miembros plenos de la comunidad moral y política. Por eso mismo, desde un punto de vista ético-político, los fenómenos actitudinales que representan la estigmatización, la invisibilización o la cosificación son barreras que, justamente, tales personas pretenden derribar mediante las luchas morales por el reconocimiento emprendidas. Son barreras que hemos de ser conscientes que es necesario derribar para salvaguardar la dignidad de cualquier persona y para sostener el trato 
que, en justicia, nos debemos mutuamente como ciudadanos.

Si la justicia tiene como fundamento el reconocimiento de la igual dignidad (Cortina, 2007) que tiene toda persona -con o sin diversidad funcional-, entonces constituye una obligación moral poner fin -en tanto que son formas de vulneración de la dignidad-a la estigmatización, la invisibilización y la cosificación a las que se somete en numerosas ocasiones a cualquier persona y, en concreto, a las personas con diversidad funcional. Se trata, en último término, de considerarlas como miembros iguales de la comunidad moral y de la comunidad política. 


\section{Referencias bibliográficas}

Abberley, P. (2008): "El concepto de opresión y el desarrollo de una teoría social de la discapacidad", en Barton, L. (comp.): Superar las barreras de la discapacidad. Madrid: Morata.

Barton, L. (comp.) (1998): Discapacidady sociedad, Madrid: Morata.

Begum, N. (I997): "Experiencias de las mujeres discapacitadas con los médicos de cabecera", en Morris, J. ( ed.): Encuentros con desconocidas. Feminismo y Discapacidad. Madrid: Narcea.

Cortina, A. (2007): Ética de la razón cordial, Oviedo: Nobel.

Etxeberria, X. (2005): Aproximación ética a la discapacidad, Bilbao: Universidad de Deusto.

Fraser, N. y Honneth, A. (2006): ¿Redistribución o reconocimiento?: un debate politico-filosófico, Madrid: Morata.

Goffman, E. (2006): Estigma: la identidad deteriorada, Buenos Aires: Amorrortu.

Honneth, A. (20I4): El derecho de la libertad. Esbozo de una eticidad democrática, Madrid: Katz.

Honneth, A. (20I I): La sociedad del desprecio, Madrid: Trotta.

Honneth, A. (2010): Reconocimiento y menosprecio. Sobre la fundamentación normativa de una teoría social, Madrid: Katz.
Honneth, A. (2009): Patologías de la razón. Historia y actualidad de la teoría crítica, Madrid: Katz.

Honneth, A. (2007): Reificación. Un estudio en la teoría del reconocimiento, Buenos Aires: Katz.

Honneth, A. (I997): La lucha por el reconocimiento. Por una gramática moral de los conflictos sociales, Barcelona: Crítica.

Kant, I. (I980): Fundamentación de la metafísica de las costumbres, México D.F.: Porrúa.

Nussbaum, M. (2007): Las fronteras de la justicia Barcelona: Paidós.

Nussbaum, M. (2006): El ocultamiento de lo humano: repugnancia, vergüenza y ley, Madrid: Katz Barpal.

Palacios, A. (2008): El modelo social de la discapacidad: orígenes, caracterización y plasmación en la Convención Internacional sobre los Derechos de las Personas con Discapacidad, Madrid: Ediciones Cinca.

Palacios, A. y Romañach, J. (2006): El modelo de la diversidad. La bioética y los derechos humanos como herramienta para alcanzar la plena dignidad en la diversidad funcional, Madrid: Diversitas.

Rawls, J. (I979): Teoría de la justicia, Madrid: F.C.E.

Young, I.M. (2000): La justicia y la política de la diferencia, Madrid: Cátedra. 